\title{
Viewing Open Source with an Open Mind
}

\begin{abstract}
Eric Allman and Marshall Kirk McKusick, Queue Advisory Board Members
\end{abstract}

W hen the first issue of ACM Queue came out, the staff did some market research to see what people most wanted to hear about. Rather to our surprise, open source came out at the top of the list. We knew open source was popular, but it seemed like every computer magazine on the planet had already dedicated at least one issue to it—in fact, several magazines are entirely devoted to the topic. Surely open source has been thoroughly explored.

But upon further reflection, perhaps this isn't true. Most writing about open source stresses the goodness (or lack of goodness) of open source as a software development model. These tend to be somewhat one-sided-you either get it or you don't. Some of the more interesting articles discussing open source have been from the economist's point of view. Since the dismal science of economics doesn't see anything as purely good or bad, these types of pieces generally make for interesting reading, in turn leading you to think a bit more carefully about the possibility that open source might be good for some things but less good for others.

As a result of this soul searching on open source, this issue of Queue largely focuses on issues that arise when open source and proprietary models meet (and sometimes clash). Companies are increasingly involved with open source in one way or another, often using it in missioncritical ways, sometimes basing their own products on open source. In a few, well-known cases, companies are producing open source as their own products. Issues such as "how you do open source development" have already been well explored, and although there is always more to learn, we chose to explore other areas rather than beat that same drum.

Bringing this issue of Queue together was harder than we expected. We tried to avoid "the usual suspects"; even though they have good points to make, they've already had adequate forum to their views. And because their lives tend to be very wrapped up in open source (often economically as well as emotionally), we had a hunch that we would get more interesting views from people who had less to lose. Even that proved harder than we had anticipated-several people declined to write, in some cases

\author{
From the \\ front lines of \\ the war BETWEEN \\ OPEN SOURCE AND \\ PROPRIETARY \\ SOFTWARE
}

\begin{abstract}
because they seemed to want to avoid saying anything controversial. That surprised us at first, but in retrospect the answer is clear: Very few people want to say anything negative
\end{abstract}

about open source if they come from a company that has staked its future on it, nor anything positive if they are employed by a non-open source company.

Nonetheless, we did pull together a great set of articles. First up, Jim Barton gives us a short history on open source followed by a discussion of how and why TiVo chose open source Linux as the base for its product. Paul Ferris follows up with a look at how corporate America views open source versus closed source, posed in the context of a religious war-religion being an all-too-apt analogy that elucidates a certain amount of animosity between the two camps, but also demonstrates that each side has something to learn from the other.

One standard distinction often comes down to use on servers versus clients. Closed source seems to own the desktop today, but there are several interesting attempts to bridge this gap (e.g., Ximian). Taking a look at one aspect of this clash of the desktops, we present the results of an ad-hoc study by the father-and-son team of Hal and Christopher Varian about the interoperability between Microsoft Office and various Linux-based office suites.

Mike Karels gives his view of making a commercial product out of open source. As one of the first to attempt this (he is a founder of BSDi), Mike has a perspective that may be a bit more mature than others' on this topic. John Weathersby also discusses the growing use of open source in government-not noted as wild and crazy guys when it comes to IT issues.

It would be too much to expect the traditional closedsource world to take this one lying down, and to produce a magazine issue on the topic of open source without mentioning the SCO-versus-IBM lawsuit would be irresponsible at best. Greg Lehey gives us an interesting perspective on all that's coming down.

To round things out, our interview this issue is with 
Chris DiBona. Although Chris's name is not as well recognized as some others, he has been an important and highly respected member of the open source community for some time. He talks with Queue about how he got into open source, working with (very) early versions of Linux, life at VA Linux, the SCO lawsuit, how he got into marketing and what that means, being an editor at Slashdot, and his new venture, Damage Studios, designing a multiuser, global game running on Linux. Oh yeah, and why he likes Microsoft's Visual Studio (no, really).

There should be something here for everyone.

ERIC ALLMAN, is the co-founder and chief technology office of Sendmail, Inc., one of the first open source companies. He was previously the lead programmer on the Mammoth Project at the University of California at Berkeley. This was his second incarnation at Berkeley; he was the chief programmer on the INGRES database management project. In addition to his assigned tasks, Allman got involved with the early Unix effort at Berkeley. His first experiences with Unix were with the 4th Edition. Over the years, Allman wrote a number of utilities that appeared with various releases of BSD, including the -me macros, tset, trek, syslog, vacation-and of course sendmail. He spent the years between the two Berkeley incarnations at Britton Lee (later Sharebase) doing database user and application interfaces, and at the International Computer Science Institute, contributing to the Ring Array Processor project for neural-net-based speech recognition. Allman also co-authored the " $\mathrm{C}$ Advisor" column for Unix Review for several years. He is a former member of the Board of Directors of Usenix Association.

MARSHALL KIRK MCKUSICK, Ph.D, has a Berkeleybased consultancy, writes books and articles, and teaches classes on Unix- and BSD-related subjects. His work with Unix stretches more than 20 years. While at the University of California at Berkeley, McKusick implemented the 4.2 BSD Fast File System and was the research computer scientist at the Berkeley Computer Systems Research Group (CSRG), overseeing the development and release of 4.3 BSD and 4.4 BSD. His areas of interest are the virtual-memory system and the file system. McKusick earned his undergraduate degree in electrical engineering from Cornell University and did his graduate work at University of California at Berkeley, where he received master's degrees in computer science and business administration and a doctorate in computer science. He is president of the Usenix Association and a member of ACM and IEEE. 